\title{
Simulation of Dew Points in Raw Biogas Using PR and SRK Equations of State
}

\author{
Terje Bråthen ${ }^{1}$ Lars Erik $\varnothing i^{1}$ Jon Hovland ${ }^{2}$ \\ ${ }^{1}$ Department of and Process, Energy and Environmental Technology, University of South-Eastern Norway \\ ${ }^{2}$ SINTEF Tel-Tek, SINTEF Industry, Porsgrunn, Norway
}

\begin{abstract}
Biogas contains mainly methane, but raw biogas can contain large amounts of $\mathrm{CO}_{2}$ and is normally saturated with water. Condensation, especially during compression, may lead to operational problems. The aim of this work is to calculate the dew point (condensation limit) under different conditions with different models in the simulation programs Aspen HYSYS and Aspen Plus. Binary coefficients for water and $\mathrm{CO}_{2}$ in these models will be fitted to experimental data from the literature. Traditionally, gas mixtures of methane, $\mathrm{CO}_{2}$ and water are calculated with standard models like Peng-Robinson (PR) and Soave-RedlichKwong (SRK). For dry biogas (mixtures with only methane and $\mathrm{CO}_{2}$ ) all the models give similar results. For a biogas mixture with 60 mol- $\%$ methane and 40 mol- $\% \mathrm{CO}_{2}$ with 0.1 mol- $\%$ added water, the models using binary coefficients fitted for binary mixtures (especially for $\mathrm{CO}_{2}$ and water), gave reasonable results up to about 70 bar, with deviations in the calculated dew point up to $8 \mathrm{~K}$. The binary coefficient for water and $\mathrm{CO}_{2}$ was fitted to experimental data from the literature for a mixture with a $\mathrm{CH}_{4}$ to $\mathrm{CO}_{2}$ molar ratio of 30/70, 50/50 and 70/30. The fitted $\mathrm{k}_{\mathrm{ij}}$ values for the PR model were $0.65,0.21$ and 0.17 , respectively. For the SRK model, the $\mathrm{k}_{\mathrm{ij}}$ values were slightly higher. At pressures below 70 bar and temperatures below $40{ }^{\circ} \mathrm{C}$, the uncertainty for calculated dewpoints in mixtures with 30 to $100 \% \mathrm{CH}_{4}$ was reduced to less than $4 \mathrm{~K}$.
\end{abstract}

Keywords: $\mathrm{CO}_{2}$, methane, water, biogas, phase envelope, Aspen HYSYS, Aspen Plus

\section{Introduction}

Bio-methane (purified biogas) contains typically 97 mole- $\%$ methane. Raw biogas typically contains $60 \%$ methane, $40 \% \mathrm{CO}_{2}$, small amounts of other components and water. The temperature where the water starts to condense from a gas is called the dew point. It is important to be able to estimate this temperature because
$\mathrm{CO}_{2}$ and water in the liquid phase is very corrosive, and may lead to operating problems. (Hovland, 2017) and (Øi and Hovland, 2018) have discussed under which conditions water containing biogas will condense under compression.

In their simulations all the models gave similar results up to about $70 \mathrm{bar}$, and some deviations above 70 bar. However, these simulations were not compared with experimental data.

Gas mixtures of methane, $\mathrm{CO}_{2}$ and water are calculated in a process simulation program with standard models like PR (Peng and Robinson, 1976) and SRK (Soave, 1972). When using fitted binary parameters (e.g., $\mathrm{k}_{\mathrm{ij}}$ parameters) these models simulate the gas phase and the condensation point reasonably accurately (within a few degrees) at least below the critical point (46 bar for methane and 74 bar for $\mathrm{CO}_{2}$ ).

Equilibrium models like HV (Huron and Vidal, 1979), TST (Twu et al., 2005) have been shown to give more accurate results, however they have more parameters which are normally not available in simulation programs like Aspen HYSYS or Aspen Plus. Other models with several parameters like SAFT-VR (Al Ghafri et al., 2014) and CPA (Austegard et al., 2006) have also been used to describe this system.

There is a limited number of articles available studying the calculations and models for vapour/liquid equilibrium in the methane $/ \mathrm{CO}_{2} /$ water-system (Austegard et al., 2006; Privat and Jaubert, 2014; Al Ghafri et al., 2014; Legoix et al., 2017). Austegard et $a l$. conclude that a simple equation of state like SRK is satisfactory to describe the vapour phase, but more complex models, e.g., SRK combined with a HV model is necessary to describe the liquid phase (Austegard et al., 2006).

Several authors have studied models for the system $\mathrm{CO}_{2}$ /water (Spycher et al., 2003; Longhi, 2005; Aasen et al., 2017). For high concentrations of $\mathrm{CO}_{2}$, it is possible to obtain two liquid phases (water rich and $\mathrm{CO}_{2}$-rich) in addition to a vapour phase. This will not occur when the $\mathrm{CH}_{4}$ content is higher than 0.225 in the vapour phase (Bi et al., 2013; Legoix et al., 2017).

Water solubility in $\mathrm{CO}_{2}$ gas or a mixture of $\mathrm{CO}_{2}$ and methane shows a minimum for a constant temperature between 50 and $100{ }^{\circ} \mathrm{C}$ at a pressure in the range of the 
critical pressures (Austegard et al., 2006; Aasen et al., 2017; Privat and Jaubert, 2014). For this system, a minimum solubility is equivalent to a maximum dew point temperature. The water solubility in pure $\mathrm{CH}_{4}$ is close to constant over a large pressure range close to the critical pressure (Privat and Jaubert, 2014).

Below $0{ }^{\circ} \mathrm{C}$, liquid water will turn into solid ice, and hydrates may also be formed. Hydrates in equilibrium in this system have been observed up to $13{ }^{\circ} \mathrm{C}$ (Al Ghafri et al., 2014) but will probably not be a problem above 0 ${ }^{\circ} \mathrm{C}$. There are several sources for experimental data for solubility of $\mathrm{CH}_{4}$ and $\mathrm{CO}_{2}$ in water (Dhima, 1999; Qin, 2008), but this is of minor interest when the main interest is in the dew point calculations.

Little experimental data has been published for the dew point (condensation limit) in the ternary system methane $/ \mathrm{CO}_{2} /$ water. (Song et al., 1990) have published experimental data for water solubility in a mixture with 5.7 mol-\% $\mathrm{CH}_{4}$ in $\mathrm{CO}_{2}$. (Jarne et al., 2004) have published data for mixtures with a molar ratio 30/70 and 80/20 for $\mathrm{CH}_{4} / \mathrm{CO}_{2}$.

(Al Ghafri et al., 2014) present dew point data for a water containing mixture of a 50/50 mixture of $\mathrm{CH}_{4}$ and $\mathrm{CO}_{2}$ at temperatures above $50{ }^{\circ} \mathrm{C}$.

The first aim of this work is to calculate the dew point for raw biogas under different temperature, pressure and gas composition (main emphasis in the region of 30 to $100 \% \mathrm{CH}_{4}$ and in the temperature range $0-50{ }^{\circ} \mathrm{C}$ ) using different equilibrium models. It is of particular interest to evaluate whether fitting data to the ternary mixture would increase the accuracy compared to using binary coefficients from only binary systems.

\section{Simulation Programs and Models}

(Øi and Hovland, 2018) used the commercial simulation program Aspen HYSYS for dry biogas $\left(\mathrm{CH}_{4}\right.$ and $\mathrm{CO}_{2}$ ) and for mixtures also containing water. The equilibrium models SRK (Soave, 1972), PR (Peng and Robinson, 1976) and TST (Twu et al., 2005) were used. In this work also the program Aspen Plus is used mainly with PR, SRK, but also some other models were tried.

The advantage with PR and SRK is that both the models and fitted binary parameters are usually available in the program.

The PR and SRK models have only one adjustable parameter for each binary component pair, but this parameter may be temperature dependent.

The equations for the SRK equation of state are shown in (1) to (8) from Aspen HYSYS Version 10. Aspen HYSYS and Aspen Plus Version 10 were used in the simulations.

Other process simulation programs like ProVision, ChemCad and ProMax also have PR and SRK and often other thermodynamic models available.

$$
\begin{aligned}
& p=\frac{R T}{v-b}-\frac{a}{v(v+b)} \\
& b=\sum_{i=1}^{N} x_{i} b_{i} \\
& b_{i}=\frac{0,08664 R T_{C}}{p_{c}} \\
& a=\sum_{i=1}^{N} \sum_{j=1}^{N} x_{i} x_{j}\left(a_{i} a_{j}\right)^{0,5}\left(1-k_{i j}\right) \\
& a_{i}=a_{c i} \alpha_{i} \\
& a_{c i}=\frac{0,42748 R^{2} T_{c}^{2}}{p_{c}} \\
& \alpha_{i}=\left[1+m_{i}\left(1-T_{r}^{1 / 2}\right)\right]^{2} \\
& m_{i}=0,48+1,574 \omega_{i}-0,176 \omega_{i}^{2}
\end{aligned}
$$

$\mathrm{P}, \mathrm{T}, \mathrm{v}$ and $\mathrm{R}$ are the pressure, temperature, molar volume and universal gas constant, respectively.

$T_{c}$ is the critical temperature, $\omega$ is the acentric factor and $T_{r}$ is the reduced temperature defined as the ratio between $T$ and $T_{c}$. The binary interaction parameter $k_{i j}$ (equal to $\mathrm{k}_{\mathrm{ji}}$ ) is a constant that may be fitted for a binary component pair and $\mathrm{x}_{\mathrm{i}}$ is the mole fraction for component $i$. In the PR equation, equation 1, 3, 6 and 8 are replaced by equation $9,10,11$ and 12 .

$$
\begin{aligned}
& p=\frac{R T}{v-b}-\frac{a}{v(v+b)+b(v-b)} \\
& b_{i}=\frac{0,077796 R T_{C}}{p_{c}} \\
& a_{c i}=\frac{0,457235 R^{2} T_{c}^{2}}{p_{c}} \\
& m_{i}=0,37464+1,54226 \omega_{i}-0,26992 \omega_{i}{ }^{2}
\end{aligned}
$$

In the standard version of SRK and PR, $\mathrm{k}_{\mathrm{ij}}$ is a constant for each binary pair. When utilizing the default $\mathrm{k}_{\mathrm{ij}}$ values in Aspen HYSYS and Aspen Plus, the $\mathrm{k}_{\mathrm{ij}}$ values are constant for all component pairs except for water/ $\mathrm{CO}_{2}$ where it is a temperature dependent function. In the literature, different optimized values for the $\mathrm{k}_{\mathrm{ij}}$ values can be found because the parameters may be optimized for different conditions, e.g., for accurate prediction of either the gas phase or the condensate phase. For the calculation of dew points, it is reasonable to use binary interaction coefficients optimized for the gas phase.

The PR and SRK versions used in Aspen Plus are equal to the Aspen HYSYS versions shown in (1) to (12), except that some of the numerical values are slightly different. Especially the coefficients in the $\mathrm{m}_{\mathrm{i}}$ expressions (8) and (12) are slightly different.

The $\mathrm{k}_{\mathrm{ij}}$ values fitted to PR and SRK models are traditionally very similar. This can be seen, e.g., for the $\mathrm{k}_{\mathrm{ij}}$ parameters in (Aasen et al., 2017). 


\section{Process Description and Simulation Specifications}

\subsection{Process description of raw biogas compression}

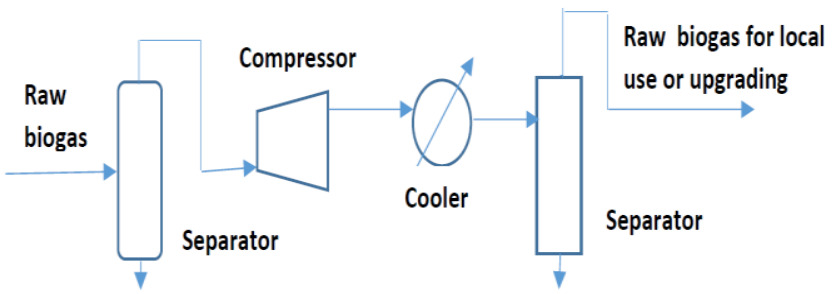

Figure 1. A traditional raw biogas compression process

The principle for a traditional raw biogas compression process is shown in Figure 1.

When the raw biogas production is high (above 100 $\mathrm{m}^{3} / \mathrm{h}$ at atmospheric pressure and ambient temperature), it can be reasonable to upgrade it on-site. For low volumes, (Hovland, 2017) suggests to compress the gas to a high pressure, typically above $100 \mathrm{bar}$, and transport it to a facility for upgrading to biomethane (almost pure methane).

As mentioned in (Øi and Hovland, 2018), condensation during compression is regarded to be a problem, and should be avoided.

\subsection{Simulation specifications}

Process simulations are performed for different conditions relevant for biogas production as in (Øi and Hovland, 2018). In earlier work the models PR, SRK, TST, PR-Twu and SRK-Twu were used. For all the conditions, calculations with the default parameters (especially the $\mathrm{k}_{\mathrm{ij}}$ for water) are used. For some conditions other $\mathrm{k}_{\mathrm{ij}}$ values are also used. It is possible to calculate phase envelopes showing the dew and bubble point curve for a temperature and pressure range. In the dry gas cases, the HYSYS 2-phase option was selected for phase envelope calculations. In the cases including water, the ComThermo 3-phase option was selected.

Verification of earlier calculations is also including calculations with Aspen Plus and with the (StryjekVera, 1986) model. In Aspen Plus the Peng-Robinson and RKSoave models were selected. The B and D cases are referring to (Øi and Hovland, 2018).

Case B: Dry biogas with 40 mol- $\%$ methane and $60 \mathrm{~mol}-$ $\% \mathrm{CO}_{2}$ starts at $37{ }^{\circ} \mathrm{C}$ and $1 \mathrm{bar}$, is cooled to $10{ }^{\circ} \mathrm{C}$ and is compressed to 64 bar.

Case D: $59.9 \mathrm{kmol} / \mathrm{h}$ methane, $40 \mathrm{kmol} / \mathrm{h} \mathrm{CO}_{2}$ and 0.1 $\mathrm{kmol} / \mathrm{h}$ water is mixed at $37{ }^{\circ} \mathrm{C}$ and $1 \mathrm{bar}$, cooled to 10 ${ }^{\circ} \mathrm{C}$, and then compressed to $64 \mathrm{bar}$.
A mixture of 30 mol- $\%$ methane and $70 \mathrm{~mol}-\% \mathrm{CO}_{2}$ mixed with a specified amount of water at a specified pressure was simulated. Calculated dew point temperatures were compared to experimental dew points from (Jarne, 2004) which were approximately 15 ${ }^{\circ} \mathrm{C}$. Binary coefficients (especially the $\mathrm{k}_{\mathrm{CO} / \mathrm{H} 2 \mathrm{O}}$ ) were varied (and fitted) to obtain the experimental dew point.

Mixtures of 50/50 and 70/30 methane to $\mathrm{CO}_{2}$ molar ratios were simulated based on experimental data from (Chapoy, 2017) with temperatures at 20 and $40{ }^{\circ} \mathrm{C}$ and

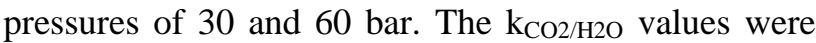
fitted also for these conditions.

\section{Process Simulation, Results and Discussion}

\subsection{Verification of earlier simulations for compression of dry methane/ $\mathrm{CO}_{2}$ mixture (Case B)}

The Aspen HYSYS flow-sheet model for the base case simulation is presented in Figure 2.

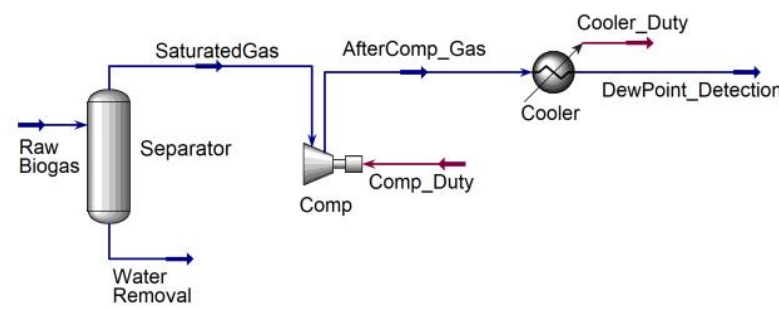

Figure 2. Aspen HYSYS flow-sheet for compression and cooling

Case B is of interest because a $40 \%$ methane and 60 $\% \mathrm{CO}_{2}$ has a dew point close to $0{ }^{\circ} \mathrm{C}$. Earlier evaluations from (Hovland, 2017) and (Øi and Hovland, 2018) have shown that below 58 mol- $\% \mathrm{CO}_{2}$, no condensation should appear if the temperature is kept above $-3{ }^{\circ} \mathrm{C}$.

Table 1. Dew point at 64 bar, cricondenterm and cricondenbar for a mixture of 40 mol- $\%$ methane and 60 mol-\% $\mathrm{CO}_{2}$ (Case B)

\begin{tabular}{|l|c|c|c|}
\hline Model & $\mathbf{T}_{\text {DEW }}$ & $\mathbf{T}_{\text {CRIC }}\left({ }^{\mathbf{0}} \mathbf{C}\right)$ & P $_{\text {CRIC }}(\mathbf{b a r})$ \\
\hline PR Hysys & -5.4 & -1.7 & 89.5 \\
\hline SRK Hysys & -5.2 & -1.3 & 88.4 \\
\hline TST Hysys & $-3,9$ & -0.5 & 82.6 \\
\hline PR-Twu Hysys & $-6,3$ & -2.7 & 90.0 \\
\hline SRK-Twu Hysys & $-5,8$ & -1.8 & 90.5 \\
\hline PR Aspen Plus & -5.4 & -1.8 & 88.2 \\
\hline SRK Aspen Plus & -5.3 & -1.6 & 87.9 \\
\hline
\end{tabular}


The results in Table 1 confirms the results from Aspen HYSYS simulation in (Øi and Hovland, 2018). In addition, similar results are obtained when PR and SRK in Aspen Plus is used. The reason why the results in Aspen HYSYS and Aspen Plus are not identical, is that the model equations are slightly different.

The calculated cricondenterms with different models have a maximum deviation of $2{ }^{\circ} \mathrm{C}$. From this it is concluded that the results can be expected to be fairly accurate for all the models evaluated. No condensation will appear above $0{ }^{\circ} \mathrm{C}$ in a dry biogas with more than 40 mole- $\% \mathrm{CH}_{4}$. This was also the conclusion from (Hovland, 2017) and (Øi and Hovland, 2018).

A phase envelope from Aspen HYSYS is shown in Figure 3. The most important part for the evaluation of condensation is the dew point curve to the right. The point with the highest temperature is the cricondenterm. The point with the highest pressure is the cricondenbar. In the critical point for the mixture, slightly to the left of the cricondenbar, the compositions in both phases are equal.

It was found that the results in Table 1 were only slightly influenced by varying the $\mathrm{k}_{\mathrm{ij}}$ parameter. The deviations are largest in the calculated envelopes above 70 bar.

It is expected that the calculations for dry biogas is reasonably accurate because all models give the same results, the parameters are fitted for this binary system and $\mathrm{CH}_{4} / \mathrm{CO}_{2}$ is a rather simple physical system.

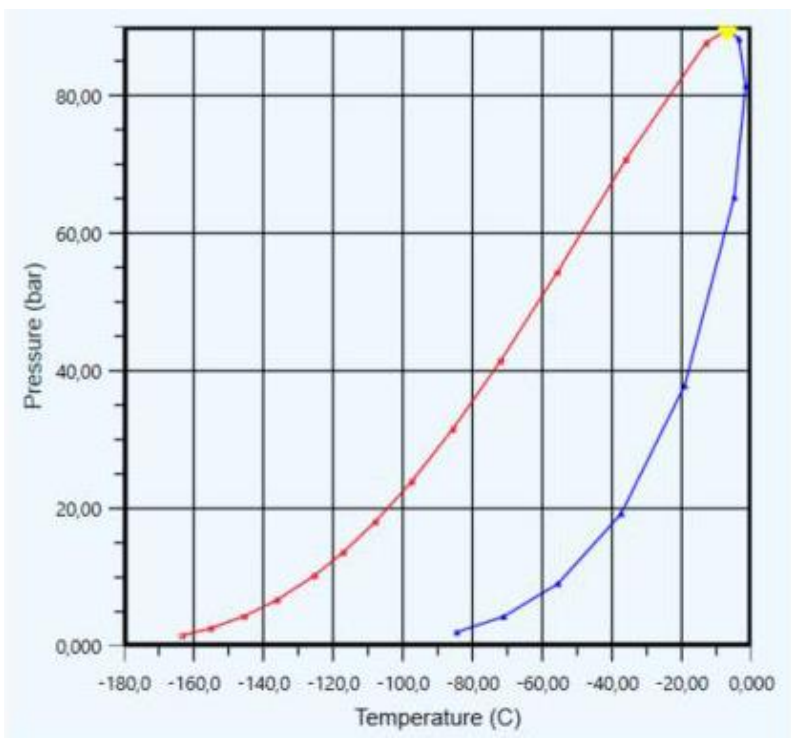

Figure 3. Phase envelope, Peng-Robinson, $\mathrm{CH}_{4}=0.4$, $\mathrm{CO}_{2}=0.6$, default $\mathrm{k}_{\mathrm{ij}}$.

\subsection{Simulation of compression of a raw biogas including water, Case D}

In Case $\mathrm{D}$, the process was simulated with water included. First the TST, PRTwu, SRKTwu default

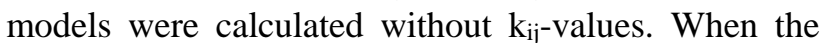
option including $\mathrm{k}_{\mathrm{ij}}$ 's for water binaries was used, the dew point temperatures were much closer to the PR and SRK models.

In Case $\mathrm{D}$, the water mole fraction was specified to 0.001 . This water concentration is possible to obtain if condensate is removed from the biogas stream after intercooling steps in the compressor. Results are shown in Table 2.

Table 2. Dew point at $64 \mathrm{bar}$, cricondenterm and pressure at cricondenterm for a mixture of $59.9 \mathrm{~mol}-\%$ methane and 40 mol- $\% \mathrm{CO}_{2}$ with $0.1 \%$ water (Case D)

\begin{tabular}{|l|c|c|c|}
\hline Model & $\mathbf{T}_{\text {DEW }}\left({ }^{\mathbf{}} \mathbf{C}\right)$ & $\mathbf{T}_{\text {CRIC }}\left({ }^{\circ} \mathbf{C}\right)$ & P $_{\text {CRICT(bar) }}$ \\
\hline PR & 26.5 & 27.6 & 89.7 \\
\hline SRK & 26.9 & 28.0 & 89.2 \\
\hline PR $\left(\mathrm{k}_{\mathrm{ij}}=0.19\right)$ & 30.0 & 34.0 & 141 \\
\hline PR $\left(\mathrm{k}_{\mathrm{ij}}=0.65\right)$ & 34.3 & none & none \\
\hline PRSV & 27.1 & 29.2 & 101 \\
\hline TST+k & 28.8 & 32.1 & 122 \\
\hline PRTwu+k & 28.5 & 32.1 & 121 \\
\hline SRKTwu+k & 28.8 & 32.2 & 122 \\
\hline
\end{tabular}

The dew point temperatures in Table 5 were also calculated in Aspen Plus. For PR and SRK the results were $26.3{ }^{\circ} \mathrm{C}$ and $27.3{ }^{\circ} \mathrm{C}$, which are very close to the Aspen Hysys values. When using HYSPR and HYSSRK in Aspen Plus the results were identical in the two programs. The model RKSMHV2 (a modified HuronVidal model) gave $29.7{ }^{\circ} \mathrm{C}$ and the model GERG2008 (from European Gas Research Group) gave $27.7^{\circ} \mathrm{C}$. There are deviations of $8 \mathrm{~K}$ between the dew point temperature dependent on $k_{i j}$ values. It is necessary to compare with experimental data to find out which models and parameters which are most accurate. 


\subsection{Fitting of binary parameters based on experimental data.}

It is reasonable to fit the binary coefficients to mixture data if we are not interested in the composition range below $30 \% \mathrm{CO}_{2}$.

It is reasonable to vary the $\mathrm{CO}_{2}$ /water and not to change the binary coefficients for the $\mathrm{CH}_{4} / \mathrm{CO}_{2}$ or the $\mathrm{CH}_{4} /$ water system. The water content is probably too low to influence on the $\mathrm{CH}_{4} / \mathrm{CO}_{2}$ interaction. The default value in $\mathrm{PR}$ is 0.1 . The $\mathrm{CH}_{4} /$ water is a much studied system. In the literature, $\mathrm{k}_{\mathrm{ij}}$ for the binary is normally specified to about 0.5 , e.g., 0.52 in (Austegard, 2006). In Aspen HYSYS, 0.5 is the default value.)

Experimental data were taken for a mixture of 30 mole- $\%$ methane, 70 mol- $\% \mathrm{CO}_{2}$ and four specified amounts of water (Jarne, 2004). The experimental data for approximately $15^{\circ} \mathrm{C}$ (the highest temperature) were selected.

The binary parameter for $\mathrm{CO}_{2}$ and water was varied until the measured dew point temperature was achieved. The results (fitted $\mathrm{k}_{\mathrm{ij}}$ values and calculated dew points) are given in Table 3 .

For a mixture with a $\mathrm{CH}_{4}$ to $\mathrm{CO}_{2}$ molar ratio of $30 / 70$, $50 / 50$ and $70 / 30$, the fitted $\mathrm{k}_{\mathrm{ij}}$ values were $0.65,0.21$ and 0.17 , respectively. These values are high compared to literature values typically between -0.1 and 0.2 (Aasen et al, 2017). The (temperature dependent) $\mathrm{k}_{\mathrm{ij}}$ values in the default PR model used in Table 3 varied between 0.12 and 0.04

The $\mathrm{k}_{\mathrm{ij}}$ values for the SRK model in Aspen HYSYS was fitted to the data from (Jarne et al., 2004) by the same procedure. The fitted $\mathrm{k}_{\mathrm{ij}}$ values were then 0.63 , 0.17 and 0.11 . The difference between the $\mathrm{k}_{\mathrm{ij}}$ values fitted to the PR and SRK models are as expected very small.

This shows that the $\mathrm{k}_{\mathrm{ij}}$ values are clearly dependent on the $\mathrm{CO}_{2}$ concentration. This supports the idea of fitting the $\mathrm{k}_{\mathrm{ij}}$ values for the concentration area of interest. For biogas this is with more than 30 mole-\% methane.

In Table 3, the dew point temperatures calculated with default PR gave mostly small deviations, but two deviations of 6.9 and $4.2 \mathrm{~K}$. The dew point temperatures were also calculated with a $\mathrm{k}_{\mathrm{ij}}$ value of 0.19 (average value for the 50/50 and 70/30 mixtures). In that case the deviations were reduced to 0.7 and $4.1 \mathrm{~K}$. This shows that uncertainty in dew point temperatures can be reduced from $7 \mathrm{~K}(8 \mathrm{~K}$ in Table 2$)$ to $4 \mathrm{~K}$ by using a constant $\mathrm{k}_{\mathrm{ij}}$ for the whole range from 30 -100 mol-\% $\mathrm{CH}_{4}$.

It was also tried to fit binary coefficients in PR and SRK to experimental data from (Al Ghafri et al., 2014) at temperatures 50 and $100{ }^{\circ} \mathrm{C}$. However, all reasonable $\mathrm{k}_{\mathrm{ij}}$ values gave deviations from the experimental dew point temperatures up to about $10 \mathrm{~K}$. This indicates that the uncertainty increases with temperature.
Table 3. Comparison of Dew points compared to experimental data from (Jarne, 2004) and PR $\mathrm{k}_{\mathrm{ij}}$ values for $\mathrm{CO}_{2} /$ water fitted to the experimental data.

\begin{tabular}{|c|c|c|c|c|c|}
\hline $\begin{array}{l}\mathbf{T}_{\text {EXP }} \\
\left({ }^{\circ} \mathbf{C}\right)\end{array}$ & $\begin{array}{l}\text { PEXP }_{\text {(bar) }} \\
\text { (bar) }\end{array}$ & $\begin{array}{l}\mathrm{CH}_{4} / \mathrm{CO}_{2} \\
\text { (mole ratio) }\end{array}$ & $\begin{array}{r}\text { Water } \\
(\mathrm{mol} \%)\end{array}$ & $\begin{array}{c}\left.\text { TPR, }{ }^{\circ} \mathrm{C}\right) \\
\mathbf{k}_{\mathrm{ij}-} \\
\text { default }\end{array}$ & $\begin{array}{c}\text { PR } \\
k_{\mathrm{ij}}{ }^{-} \\
\text {fitted }\end{array}$ \\
\hline 14.7 & 31.6 & $30 / 70$ & 0.0547 & 7.8 & 0.65 \\
\hline 14.8 & 20.7 & $30 / 70$ & 0.0844 & 10.9 & 0.60 \\
\hline 14.8 & 11.9 & $30 / 70$ & 0.1400 & 12.3 & 0.70 \\
\hline 20 & 30 & $50 / 50$ & 0.0989 & 18.6 & 0.15 \\
\hline 20 & 60 & $50 / 50$ & 0.0636 & 15.9 & 0.20 \\
\hline 40 & 30 & $50 / 50$ & 0.2961 & 38.3 & 0.24 \\
\hline 40 & 60 & $50 / 50$ & 0.1791 & 35.8 & 0.25 \\
\hline 20 & 30 & $70 / 30$ & 0.0959 & 19.5 & 0.10 \\
\hline 20 & 60 & $70 / 30$ & 0.0584 & 18.1 & 0.15 \\
\hline 40 & 30 & $70 / 30$ & 0.2873 & 39.1 & 0.20 \\
\hline 40 & 60 & $70 / 30$ & 0.1693 & 37.9 & 0.21 \\
\hline
\end{tabular}

\subsection{Phase envelope calculations}

The phase envelope for PR with $\mathrm{k}_{\mathrm{ij}}=0.19$ from Table 2 is shown in Figure 4.

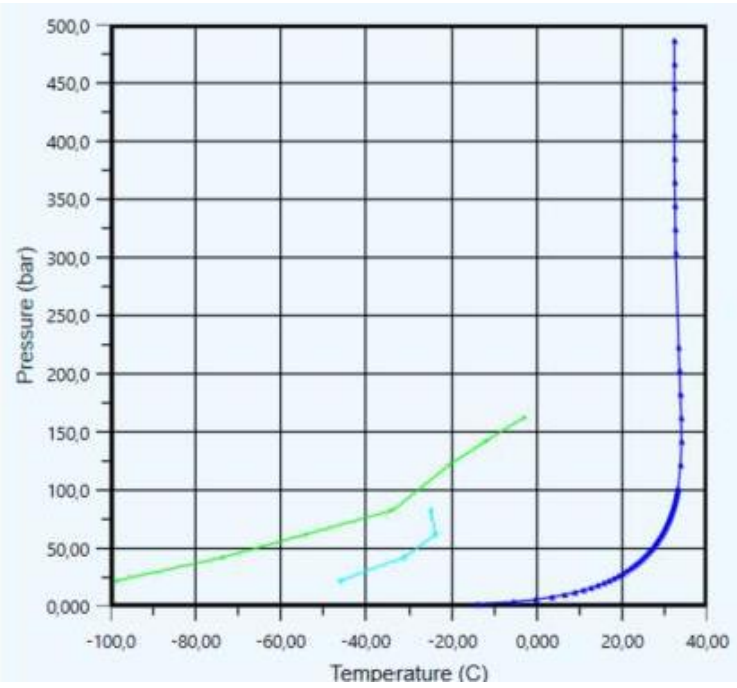

Figure 4. Phase envelope for PR model, 59,9 $\mathrm{mol}_{\%} \mathrm{CH}_{4}$, $40 \mathrm{~mol} \% \mathrm{CO}_{2}, 0.1 \mathrm{~mol} \%$ water: $\mathrm{k}_{\mathrm{ij}}=0.19$ for water $/ \mathrm{CO}_{2}$

The envelopes in Case D are similar for the different models up to about 70 bar. Above 70 bar there is however a difference up to $4 \mathrm{~K}$ between the models. The differences are due to the model and the model parameters, especially the $\mathrm{k}_{\mathrm{ij}}$ for water and $\mathrm{CO}_{2}$. The difference between the models above 70 bar is significant. 
As mentioned by (Øi and Hovland, 2018), it is reasonable that the non-ideality and uncertainty increases when the pressure increases, and also when the mixture is close to condensation and close to the critical point which is order of magnitude 70 bar. The range with an uncertainty less than $4 \mathrm{~K}$ in calculated dew point with PR or SRK with one constant $\mathrm{k}_{\mathrm{ij}}$ value (0.19) is for the range of temperatures $0-40^{\circ} \mathrm{C}$, pressures up to $70 \mathrm{bar}$ and $\mathrm{CH}_{4}$ concentration above 30 mol- $\%$.

\section{Conclusion}

Dew points for dry and raw biogas under different conditions with varied temperature, pressure and gas composition using different equilibrium models have been calculated.

For dry biogas, all the models Peng-Robinson (PR), Soave-Redlich-Kwong (SRK), PRSV, both in Aspen HYSYS and Aspen Plus gave similar results. As in the literature, above $0{ }^{\circ} \mathrm{C}$ a biogas mixture with more than $40 \%$ methane will not result in any condensation.

A process is simulated where raw biogas is compressed and cooled. From the results with biogas containing water at low pressure, the different models gave similar results within a few $\mathrm{K}$ up to about 70 bar. The deviation compared to experimental values were however up to $8 \mathrm{~K}$. The results were dependent on the chosen value of the water/ $\mathrm{CO}_{2}$ binary interaction coefficient.

The binary coefficient for water and $\mathrm{CO}_{2}$ was fitted to experimental data from the literature for a mixture with a $\mathrm{CH}_{4}$ to $\mathrm{CO}_{2}$ molar ratio of $30 / 70,50 / 50$ and 70/30. The fitted $\mathrm{k}_{\mathrm{ij}}$ values for the PR model were 0.65 , 0.21 and 0.17 , respectively. For the SRK model, the $\mathrm{k}_{\mathrm{ij}}$ values were slightly higher. At pressures below 70 bar and temperatures below $40{ }^{\circ} \mathrm{C}$, the uncertainty for calculated dew-points in mixtures with 30 to $100 \% \mathrm{CH}_{4}$ was reduced to less than $4 \mathrm{~K}$.

\section{References}

A. Aasen, M. Hammer, G. Skaugen, J. P. Jakobsen, and $\varnothing$. Wilhelmsen. Thermodynamic models to accurately describe the PVTxy-behaviour of water/carbon dioxide mixtures, Fluid Phase Equilibria, 442:125-139, 2017.

S. Z. S. Al Ghafri, E. Forte, G. C. Maitland, J.J. RodriguezHenriquez, and J. P. M. Trusler. Experimental and Modeling Study of the Phase Behaviour of (Methane + $\mathrm{CO} 2$ + Water) Mixtures. Journal of Physical Chemistry, 118:14462-14478, 2014.

A. Austegard, E. Solbraa, G. de Koeijer, and M. J. Mølnvik. Thermodynamic models for calculating mutual solubilities in $\mathrm{H}_{2} \mathrm{O}-\mathrm{CO}_{2}-\mathrm{CH}_{4}$ mixtures. Trans IChemE, Part A, Chem. Eng. Res. Des., 84(A9):781-7946, 2006.
Y. Bi, T. Yang and K. Guo. Determination of the upper quadruple phase equilibrium region for carbon dioxide and methane mixed gas hydrates. Journal of Petroleum Science and Engineering, 101:62-67, 2013.

A. Chapoy, R. Burgass, A. Terrigeol, and C. Coquelet. Water Content of $\mathrm{CH} 4$ rich Mixtures: Measurements and Modeling using the Cubic-Plus-Association Equation of State. Journal of Natural Gas Engineering, 1(13):8597, 2016.

A. Dhima, J. de Hemptinne, and J. Jose. Solubility of Hydrocarbons and $\mathrm{CO}_{2}$ Mixtures in Water under High Pressure. Ind. Eng. Chem. Res., 38:3144-3169, 1999.

J. Hovland. Compression of raw biogas - A feasibility study. Tel-Tek report 2217020-1, 2017. Available on https://www.biogas2020.se/wp-content/uploads/2017/06/ 2217020-1compressionrawbiogas.pdf

M. J. Huron and J. Vidal. New mixing rules in simple equations of state for representing vapour-liquid equilibria of strongly non-ideal mixtures. Fluid Phase Equilibria, 3:255-271, 1979.

C. Jarne, S. T. Blanco, M. A. Gallardo, E. Rauzi, S. Otin, and I. Valesco. Dew Points of Ternary Methane (or Ethane) + Carcon Dioxide + Water Mixtures: Measurements and Correlation. Energy \& Fuels, 18:396-404, 2004.

L. N. Legoix, L. Ruffine, J. P. Donval, and M. Haeckel. Phase Equilibria of the CH4-CO2 Binary and the CH4$\mathrm{CO}_{2}-\mathrm{H}_{2} \mathrm{O}$ Ternary Mixtures in the Presence of a CO2Rich Liquid Phase. Energies, 10(2034):1-11, 2017. doi:10.3390/en10122034.

J. Longhi. Phase equilibria in the system CO2-H2O I: New equilibrium relations at low temperatures. Geochimica et Cosmochimica Acta, 69, No. 3: 529-539, 2005.

D. Peng and D. B. Robinson. A New Two-Constant Equation of State. Ind. Eng. Chem. Fundam., 15(1):59-646, 1976.

R. Privat and J. N. Jaubert, Predicting the Phase Equilibria of Carbon Dioxide Containing Mixtures Involved in CCS Processes Using the PPR78 Model. InTech, 2014. Available on http://dx.doi.org/10.5772/57058.

J. Qin, R. J. Rosenbauer, and Z. Duan. Experimental Measurements of Vapor-Liquid Equilibria of the $\mathrm{H} 2 \mathrm{O}$ $+\mathrm{CO} 2+\mathrm{CH} 4$ Ternary System. Journal of Chemi cal Engineering Data, 53:1246-1249, 2008.

G. Soave. Equilibrium constants from a modified RedlichKwong equation of state. Chemical Engineering Science, 27:1197-1203, 1972.

K. Y. Song and R. Kobayashi. The water content of a CO2rich gas mixture containing $5.31 \mathrm{~mol} \%$ methane along three-phase and super-critical conditions. Journal of Chemical Engineering Data, 35(3):320-322, 1990.

N. Spycher, K. Pruess, and J. Ennis-King. CO2-H2O mixtures in the geological sequestration of $\mathrm{CO} 2$. I. Assessment and calculation of mutual solubilities from 12 to $100{ }^{\circ} \mathrm{C}$ and up to 600 bar. Geochimica et Cosmochimica Acta, 67 (16):3015-3031, 2003.

R. Stryjek and J. H. Vera. PRSV - An Improved PengRobinson Equation of State with New Mixing Rules for Strongly Nonideal Mixtures. The Canadian Journal of Chemical Engineering, 64:334-340, 1986.

C. H. Twu, D. Bluck, J. R. Cunningham, and J. E. Coon. A Cubic Equation of State with a New Alpha Function and a New Mixing Rule. Fluid Phase Equilibria, 69:33-50, 1991.

L. E. Øi and J. Hovland. Simulation of Condensation in Compressed Raw Biogas Using Aspen HYSYS. In Linköping Electronic Conference Proceedings SIMS 59, pages 31-36, 2018. doi: 10.3384/ecp1815331. 